\title{
Performance of Nymph and Adult of Piezodorus guildinii (Westwood) (Hemiptera: Pentatomidae) Feeding on Cultivated Legumes
}

\author{
MS Zerbino ${ }^{1}$, NA ALTIER ${ }^{1}$, AR PANIZZI ${ }^{2}$ \\ ${ }^{1}$ INIA La Estanzuela, Colonia, Uruguay \\ ${ }^{2}$ EMBRAPA Trigo, Passo Fundo, RS, Brasil
}

\section{Keywords}

Biology, forage legumes, red banded stink bug

\section{Correspondence}

MS Zerbino, INIA La Estanzuela, Ruta 50 km11, Colonia, Uruguay; szerbino@inia.org. uy

Edited by Christian S Torres - UFRPE

Received 13 January 2015 and accepted 21 October 2015

Published online: 18 November 2015

(C) Sociedade Entomológica do Brasil 2015

\begin{abstract}
Performance of nymphs and adults of Piezodorus guildinii (Westwood) feeding on different cultivated legumes was studied under controlled laboratory conditions $\left(25 \pm 1^{\circ} \mathrm{C}, 80 \pm 10 \% \mathrm{RH}, 14 \mathrm{~h}\right.$ of photophase) on soybean immature pod (SIP; R5.5-R6), birdsfoot trefoil immature pod (BTIP), alfalfa immature pod (AIP), and red clover flower with immature seeds (RCF). Food had significant effects on the life history of $P$. guildinii. The major differences in nymph survivorship were observed at second and third instars, with similar survivorship on SIP and AIP as hosts and higher than that recorded on BTIP and RCF. Total nymph mortality was much greater on BTIP (87.6\%) than on SIP (32.6\%) and AIP (54.2\%); all nymphs died on RCF. Food did not affect nymph development time (about 20 days). Adult longevity was highest and lowest on AIP and RCF ( 62 and 32 days), respectively. Percentage of ovipositing females was highest ( $\approx 80 \%)$ on SIP and AIP, and intermediate on BTIP (52.2\%); no females reproduced on RCF. Fecundity on SIP and AIP was similar ( $\approx 9$ egg masses/female; and $\approx 141$ eggs/female) and twice as higher than on BTIP (4.1 egg masses/female; and 60.2 eggs/female). Egg fertility (58\%) did not vary with food sources. Adults fed on SIP and AIP gained weight during 43 days, remained unaltered on BTIP, and decreased on RCF. Data obtained indicated that SIP and AIP are suitable food sources, and emphasize the importance of alfalfa as a host plant of $P$. guildinii in Uruguay.
\end{abstract}

\section{Introduction}

Piezodorus guildinii (Westwood) is a Neotropical stink bug species ranging from Argentina to southern USA (Panizzi \& Slansky 1985). It is an important pest of soybean in the Southern Cone of South America and the most abundant stink bug in Uruguay and Argentina, being more common than the cosmopolitan southern green stink bug, Nezara viridula (L.). It is the less polyphagous stink bug, having a particular preference for legumes, feeding on a wide range of cultivated and non-cultivated host plants (Panizzi \& Slansky 1985). The list of plants that $P$. guildinii feeds includes other economically important crops as common bean Phaseolus vulgaris, pea Pisum sativum, lentil Lens culinaris, and forage legumes such as alfalfa Medicago sativa and birdsfoot trefoil Lotus corniculatus, besides soybean Glycine max (Panizzi \& Slansky 1985, Panizzi 1997, Panizzi et al 2000, Ribeiro et al 2009, Zerbino et al 2014).

Piezodorus guildinii explores different host plants within and between generations because nymphs and adults feed on the temporally restricted fruiting structures of plants (Kiritani et al 1965, Jones \& Sullivan 1982, Panizzi \& Meneguim 1989, Panizzi 1997, Panizzi \& Parra 2009, Zerbino et al 2014). In general, P. guildinii spends only a third of the year feeding on its favorite plant soybean, but when this host plant is not available, the insect is forced 
to colonize other plants, which can be used as a source of food or shelter, allowing $P$. guildinii to maintain populations over time (Panizzi 1997, 2000). Due to the geographical distribution of plant species, local populations of stink bugs have specific food habits; for that reason, it is necessary to know in each locality the role of different plants in the biology of nymphs and adults (Panizzi \& Slansky 1985, Panizzi 1997, 2000, Panizzi \& Parra 2009).

Results obtained in a field survey conducted in the southwestern shore of Uruguay indicated that $P$. guildinii inhabits forage legumes (alfalfa, birdsfoot trefoil, red clover Trifolium pratense) almost the entire year (Zerbino et al 2014). No information is available about the impact these plants have on insect development. Based on this knowledge, it is possible to establish which plants are the most important in the life history of the insect in order to concentrate studies on them, and to develop management tactics to mitigate the buildup of $P$. guildinii populations (Panizzi 1997, Panizzi \& Parra 2012). The current laboratory study was carried out to evaluate the performance of nymphs and adults of $P$. guildinii feeding on the main forage legumes (alfalfa, birdsfoot trefoil, and red clover) cultivated in Uruguay, and soybean, which was deemed as control.

\section{Material and Methods}

\section{Insects, origin, and routine maintenance}

Adults of $P$. guildinii were collected during spring in 2013 at INIA La Estanzuela, Colonia, Uruguay ( $34^{\circ} 20^{\prime} \mathrm{S}, 57^{\circ} 41^{\prime} \mathrm{W}$ ) and taken to the laboratory. Each one of the 20 pairs was placed singly in a clear plastic box $(25 \times 20 \times 20 \mathrm{~cm})$ to obtain eggs (Silva \& Panizzi 2008). They were fed with green pods of $P$. vulgaris, dry soybean seeds, and raw shelled peanuts Arachis hypogaea, all equally available, a standard diet routinely used to rear stink bugs in the laboratory (Silva \& Panizzi 2007). Food source was replaced on alternate days, and distilled water was supplied every day by using moistened cotton in a plastic container (1.0-cm diameter). Egg masses were removed and conditioned in Petri dishes $(9.0 \times 1.5 \mathrm{~cm})$ lined with moistened filter paper and then carried to environmental chambers where experiments were performed. The environmental chambers were maintained at $25 \pm 1^{\circ} \mathrm{C}, 80 \pm 10 \% \mathrm{RH}$, and 14 -h photophase (four lights of light type Day TLT 20W/54 RS arranged vertically on the door). Temperatures and humidity were monitored every day using HOBO data loggers (model U23-001, Onset Computer, Pocasset, MA). Food sources considered in both nymph and adult biology were alfalfa immature pods (AIP), birdsfoot trefoil immature pods (BTIP), red clover flower with immature seeds (RCF), and soybean immature pods (SIP) at R5-6 stage.

\section{Nymph performance}

During the first instar, nymphs were maintained only with distilled water. On the first day of the second instar, when feeding activity started, individualized nymphs were placed each in a crystal polystyrene box $(11.0 \times 11.0 \times 3.5 \mathrm{~cm})$ lined with moistened filter paper. Since that moment, they began to receive the different food sources, alfalfa immature pods (AIP), birdsfoot trefoil immature pods (BTIP), red clover flower with immature seeds (RCF), and soybean immature pods (SIP) at R5-6 stage. Approximately 50 nymphs (replicates) were used for each treatment. Food source was replaced on alternate days, and distilled water was supplied every day by using moistened cotton in a plastic container (1.0$\mathrm{cm}$ diameter).

Daily observations were made on molting and mortality. The mean nymph development time, percentage of survivorship of each instar (except the first), and total mortality from second to adult were calculated. Fresh body weight $(\mathrm{mg})$ at adult emergence was taken using an electronic scale (OHAUS Pioneer TM; to the nearest $0.1 \mathrm{mg}$ ). Treatments were set up in a completely randomized design.

\section{Adult performance}

During the first instar, nymphs were maintained only with distilled water. On the first day of the second instar, groups of ten nymphs were placed each in a crystal polystyrene box $(11.0 \times 11.0 \times 3.5 \mathrm{~cm})$ lined with moistened filter paper. They were fed with green pods of $P$. vulgaris, dry soybean seeds, and raw shelled peanuts. Food source was replaced on alternate days and distilled water was supplied every day by using moistened cotton in a plastic container (1.0-cm diameter).

At adult emergence, more than 50 single pairs were individualized in crystal polystyrene boxes $(11.0 \times 11.0 \times 3.5 \mathrm{~cm})$ lined with moistened filter paper and fed with alfalfa immature pods (AIP), birdsfoot trefoil immature pods (BTIP), red clover flower with immature seeds (RCF), and soybean immature pods (SIP) at R5-6 stage. Food and water were provided as described for the nymph study. Daily records were made of adult mortality, female oviposition, and eggs laid and hatched. Percentage of adult survival up to day 98, total longevity, percentage of ovipositing females, preoviposition period, fecundity (mean number of egg masses and eggs/female), and percentage of viability were calculated. Fresh body weight $(\mathrm{mg})$ for both sexes was taken at the moment of the adult emergence and once a week thereafter until mortality, using an electronic scale (OHAUS Pioneer ${ }^{\mathrm{TM}}$; to the nearest $0.1 \mathrm{mg}$ ). Males and females that died were not 
replaced. Treatments were set up in a completely randomized design, and each pair was considered a replicate.

\section{Statistical analysis}

The experiments were replicated twice. Because results from the two experiments were similar, data were combined in the final statistical analyses.

Nymph survivorship and total mortality and percentage of ovipositing females were analyzed using generalized linear model with binomial distribution and link function logit (PROC GENMOD, SAS Institute 2008, version 9.2). Results are presented as the likelihood ratio statistics of the chi square distribution.

Instar duration and total nymph development time, preoviposition period, number of egg masses and total eggs per female, and adult longevity were analyzed with the generalized linear model with Poisson distribution or negative binomial and logarithmic function (PROC GENMOD, SAS Institute 2008, version 9.2), as they are discrete variables, and an association between means and variance was detected. The results are presented as the likelihood ratio statistics of the chi square distribution.

The weight at adult emergence and the percentage of egg viability were analyzed using the general linear model (PROC GLM, SAS Institute 2008, version 9.2) due to the fact that the variance was homogeneous, and there was no association between means and variance. Means were compared using Tukey-Kramer honestly significant (HSD) test for significance $(p \leq 0.05)$. Differences between male and female fresh body weight were compared using Student's $t$ test $(p \leq 0.05)$.

Data on percentage of adult survival over time for each food source were analyzed by simple linear regression. To comply with the assumptions of linear regression, data were transformed to $\ln (x+1)$. Slope coefficients were compared using Student's $t$ test $(p \leq 0.05)$.

Data regarding change in fresh body weight were analyzed using the general linear mixed model (Proc MIXED, SAS Institute 2008, version 9.2), with initial body weight (measured at day 1) as a covariate and the subsequent weights as repeated measures in the analysis. The covariance structure that fitted the data was ANTE (1). The model statement included the interaction term (food and age) to test for heterogeneity of slopes.

\section{Results}

\section{Nymph performance}

Nymph development time during from second to fourth instar varied significantly among food sources (second, $\chi^{2}=$ 21.8, $d f=3, p<0.0001$; third, $\chi^{2}=23.1, d f=3, p<0.0001$; and fourth, $\chi^{2}=5.9, d f=2, p=0.05$ ), but not during the fifth instar $\left(\chi^{2}=1.2, d f=2, p=0.56\right)$. No RCF nymphs reached up to the third instar; in both second and third instars, nymphs took significantly more time than on AIP, BTIP, and SIP, for which the time taken to complete these instars was similar. At fourth instar, nymphs on AIP and SIP complete development faster than on BTIP (Table 1). On those food sources in which $P$. guildinii nymphs completed development, the time required to reach adulthood (second through fifth instar) in both sexes was similar (females, $\chi^{2}=0.7, d f=1, p=0.70$; males, $\chi^{2}=3.2, d f=1, p=0.20$; Table 1).

Nymph survivorship between second and fifth instars was affected by food sources (second, $\chi^{2}=69.8, d f=3, p<0.0001$; third, $\chi^{2}=63.0, d f=3, p<0.0001$; fourth, $\chi^{2}=8.9, d f=3, p=$ 0.03 ; and fifth, $\left.\chi^{2}=15.6, d f=2, p=0.0004\right)$. Nymph survivorship at the second and third instars on alfalfa immature pods (AIP), and soybean immature pods (SIP) was similar and significantly higher than on birdsfoot trefoil immature pods (BTIP), and red clover flower with immature seeds (RCF); according to the likelihood ratio statistics of the chi square distribution, the lowest value of nymphal survivorship was obtained on RCF (Fig 1). No nymph on RCF completed fourth instar, and on BTIP, AIP, and SIP, recorded values were similar. During the fifth instar, nymph survivorship was highest and lowest on SIP and BTIP, respectively (Fig 1).

Total nymph mortality (second and fifth instars) varied significantly among food sources $\left(\chi^{2}=151.5, d f=3\right.$, $p<0.0001)$. Values recorded for each food sources were different, $100 \%$ on RCF, $87.6 \%$ on BTIP, $54.2 \%$ on AIP, and $32.6 \%$ on SIP (Table 1).

Food sources did not affect fresh body weight of 1-day-old females $\left(F_{2,41}=0.2, p=0.81\right)$, but they had significant effects on fresh body weights of males newly emerged $\left(F_{2,27}=3.9\right.$, $p=0.03$ ). Males on AIP were lighter than those fed on SIP, while on BTIP, the average value of fresh body weight was intermediate. Within the same food source, females were significantly heavier than males when nymphs fed on BTIP and AIP, but both sexes had similar fresh body weight when fed on SIP (Table 2).

\section{Adult performance}

Adult survivorship gradually decreased over time in all treatments. It followed a similar pattern on all food sources tested, except when fed on red clover flower with immature seeds (RCF, Fig 2).

Adults of both sexes fed on RCF had a significantly lower survivorship rate than on alfalfa immature pods (AIP), birdsfoot trefoil immature pods (BTIP), and soybean immature pods (SIP), which were similar to each other (Table 3). At day 50 of adult emergence, only $22 \%$ of females and $17 \%$ of males survived on RCF, while on the remaining food sources, survivorship ranged between 59 (BTIP) and 69\% (AIP) for 
Table 1 Development time (mean \pm SEM) and mortality of Piezodorus guildinii nymphs, feeding on red clover flower with immature seeds (RCF), birdsfoot trefoil immature pods (BTIP), alfalfa immature pods (AIP), and soybean immature pods (SIP), in the laboratory.

\begin{tabular}{|c|c|c|c|c|c|c|c|c|}
\hline \multirow[t]{2}{*}{ Food sources } & \multirow[t]{2}{*}{ Initial number } & \multicolumn{4}{|c|}{ Instar duration (days) } & \multicolumn{2}{|c|}{ Total development time (2nd-5th instars) (days) } & \multirow[t]{2}{*}{ Total mortality (\%) } \\
\hline & & 2nd & $3 r d$ & 4th & 5 th & Female & Male & \\
\hline RCF & 96 & $\begin{array}{l}7.6 \pm 0.6 a^{a} \\
{[22]}\end{array}$ & $\begin{array}{l}12.5 \pm 4.5 \mathrm{a} \\
{[2]}\end{array}$ & - & - & - & - & $100.0 \mathrm{a}$ \\
\hline BTIP & 109 & $\begin{array}{l}5.1 \pm 0.4 \mathrm{~b} \\
{[40]}\end{array}$ & $\begin{array}{l}4.3 \pm 0.3 \mathrm{~b} \\
{[27]}\end{array}$ & $\begin{array}{l}6.1 \pm 0.6 \mathrm{a} \\
{[21]}\end{array}$ & $\begin{array}{l}6.4 \pm 0.3 \mathrm{a} \\
{[14]}\end{array}$ & $21.3 \pm 0.8 a$ & $22.7 \pm 1.0 \mathrm{a}$ & $87.6 \mathrm{~b}$ \\
\hline AIP & 59 & $\begin{array}{l}5.0 \pm 0.3 \mathrm{~b} \\
{[45]}\end{array}$ & $\begin{array}{l}4.5 \pm 0.3 \mathrm{~b} \\
{[39]}\end{array}$ & $\begin{array}{l}4.6 \pm 0.3 \mathrm{~b} \\
{[33]}\end{array}$ & $\begin{array}{l}6.0 \pm 0.3 \mathrm{a} \\
{[27]}\end{array}$ & $20.6 \pm 0.5 a$ & $19.0 \pm 0.5 \mathrm{a}$ & $54.2 \mathrm{c}$ \\
\hline SIP & 50 & $\begin{array}{l}4.6 \pm 0.1 \mathrm{~b} \\
{[38]}\end{array}$ & $\begin{array}{l}3.7 \pm 0.1 \mathrm{~b} \\
{[37]}\end{array}$ & $\begin{array}{l}4.4 \pm 0.1 \mathrm{~b} \\
{[33]}\end{array}$ & $\begin{array}{l}6.7 \pm 0.2 \mathrm{a} \\
{[33]}\end{array}$ & $19.7 \pm 0.5 \mathrm{a}$ & $19.3 \pm 0.4 \mathrm{a}$ & $32.6 \mathrm{~d}$ \\
\hline
\end{tabular}

${ }^{a}$ Means in each column followed by the same letters are not significantly different $(p<0.05)$ based on likelihood ratio (initial number of nymphs surviving each stadium is given in brackets)

females, and between 39 (BTIP) and 75\% (AIP) for males (Fig 2).

Adult longevity was affected by food source (females, $\chi^{2}=$ 37.4; males, $\left.\chi^{2}=38.6 ; d f=3, p<0.0001\right)$. Longevity varied between 68 days (AIP) and 32 days (RCF) for both sexes (Table 3). No differences were found between values recorded on SIP ( 54 days) and BTIP ( 50 days, Table 3).

Reproductive performance of Piezodorus guildinii varied among food sources. Percentage of ovipositing females $\left(\chi^{2}=\right.$ 21.3, $d f=2, p<0.0001)$ was highest when fed on AIP (87.7\%) and SIP (83.8\%), while only $52.2 \%$ of ovipositing females were observed on BTIP and none on RCF (Table 4).

On those food sources on which females were able to reproduce, the preoviposition period $\left(\chi^{2}=6.6, d f=2, p=\right.$ 0.04 ) was shortest and longest on AIP (18.6 days) and

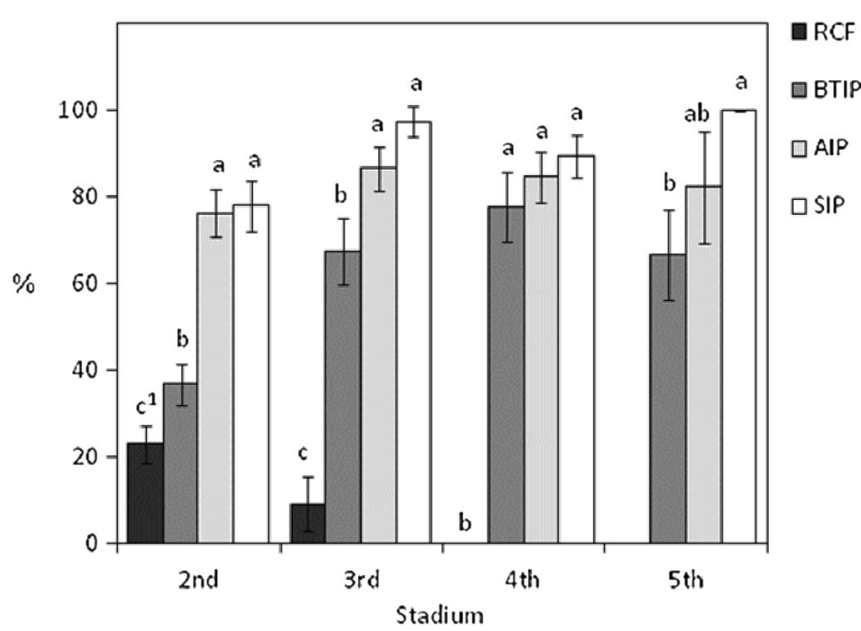

Fig 1 Survivorship (mean \pm SEM) of Piezodorus guildinii nymphs at different instars feeding on red clover flower with immature seeds (RCF), birdsfoot trefoil immature pods (BTIP), alfalfa immature pods (AIP), and soybean immature pods (SIP), in the laboratory. ${ }^{1}$ Means in each instar followed by the same letters are not significantly different $(p<0.05)$ based on likelihood ratio.
SIP (25.8 days), respectively, and intermediate on BTIP (21.1 days, Table 4). Food sources significantly affected fecundity (egg masses/female, $\chi^{2}=17.94, d f=2$, $p<0.0001$; eggs/female, $\chi^{2}=15.0, d f=2, p=0.0005$ ). Females feeding on AIP and SIP laid a significantly greater number of egg masses/female (8.5 and 9.9, respectively) and number of eggs/female (134.4 and 148.3, respectively) than those fed on BTIP (4.1 egg masses/female and 60.2 eggs/female). Food sources did not have effects on egg viability $\left(F_{2,125}=0.06, p=0.94\right.$; Table 3$)$.

Body weight gain of adults varied significantly with the food source during the first 43 days of adulthood (interaction food and age, $F_{4,1464}=25.4, p<0.0001$ ). The effects of the food source were similar in both sexes (interaction food and sexes, $F_{3,241}=1.5, p=0.22$ ). According to the slope of the linear regression, adults fed on AIP and SIP gained weight during this period; while insects feeding on BTIP kept the initial weight, those fed on RCF lost weight (Table 5). Changes in the weight of females were higher than in males (Fig 3a, b). Females on AIP never lost weight during the 43 days of adult life, while those fed on RCF only gained weight during the third week of adult life (15-22 days, Fig 3a). Males feeding on AIP only lost weight between the fifth and sixth weeks of adult life, while those fed on RCF never gained weight during their 43 days of adult life (Fig 3 b).

\section{Discussion}

Our data indicate that different aspects of the biology of nymphs and adults of $P$. guildinii were affected by the tested food sources. Besides, results helped to determinate the role that forage legumes (alfalfa, red clover and lotus) play on the life history of this insect. The variable impact of the different plant species on the performance of 
Table 2 Fresh body weight (mean \pm SEM) of Piezodorus guildinii at adult emergence feeding on birdsfoot trefoil immature pods (BTIP), alfalfa immature pods (AIP), and soybean immature pods (SIP), in the laboratory.

\begin{tabular}{lll}
\hline & \multicolumn{2}{l}{ Fresh body weight $^{\mathrm{a}}(\mathrm{mg})$} \\
\cline { 2 - 3 } Food sources & Female & Male \\
\hline BTIP & $53.4 \pm 2.3 \mathrm{aA}$ & $44.6 \pm 2.4 \mathrm{abB}$ \\
AIP & $52.6 \pm 1.6 \mathrm{aA}$ & $43.1 \pm 3.2 \mathrm{bB}$ \\
SIP & $51.2 \pm 2.5 \mathrm{aA}$ & $49.3 \pm 1.1 \mathrm{aA}$ \\
\hline
\end{tabular}

${ }^{a}$ Means followed by the same lowercase letters in each column and uppercase letter in each row do not differ significantly $(p<0.05)$ using Tukey's test and $t$ test, respectively.

nymphs and adults was the consequence of the physical and chemical attributes (nutrients and non-nutrients) that they have (Panizzi 1987, Panizzi \& Silva 2009). Although in several countries in South America $P$. guildinii is known as the "Alfalfa stinkbug," no data in the literature were found about nymph and adult biology performed on alfalfa and/or other forage legumes.

Although the tested food sources that allowed full development had similar impact on nymph development time, they had different effects on nymph survival. Scriber \& Slansky (1981) stated that the nutritional quality of the food (energy, nutrients, and allelochemicals) has significant effects on the survival and growth of immature arthropods that cause changes in the rates of food digestibility and nutrient assimilation.

On red clover flower with immature seeds (RCF), no nymphs reached adulthood; much probably the nutritional suitability of this plant structure is inadequate. This result may seem contradictory to that obtained by Zerbino et al (2014), who reported the presence of nymphs on this plant species between November and April. One possible explanation is that nymphs could have been originated from egg masses eventually deposited by females that temporarily colonized this crop, in the absence of other food sources (Panizzi \& Silva 2009). Nymphs may be seriously threatened on a food source that prevents their development, i.e., red clover (Panizzi et al 1980, 2000, Panizzi 2007, Panizzi \& Silva 2009). It could also be possible that nymphs observed in red clover could have been older (fourth and fifth instars), coming from other plant species. Panizzi et al (1980) reported that at these stages, P. guildinii can disperse and, like adults, temporarily colonize alternate plants in the absence of other food sources. Older nymphs may have different food habits from those of young nymphs (Panizzi 1997), so they may likely survive on red clover.

Due to the low nymph survivorship recorded on BTIP, mainly at the second instar, total nymph mortality was very
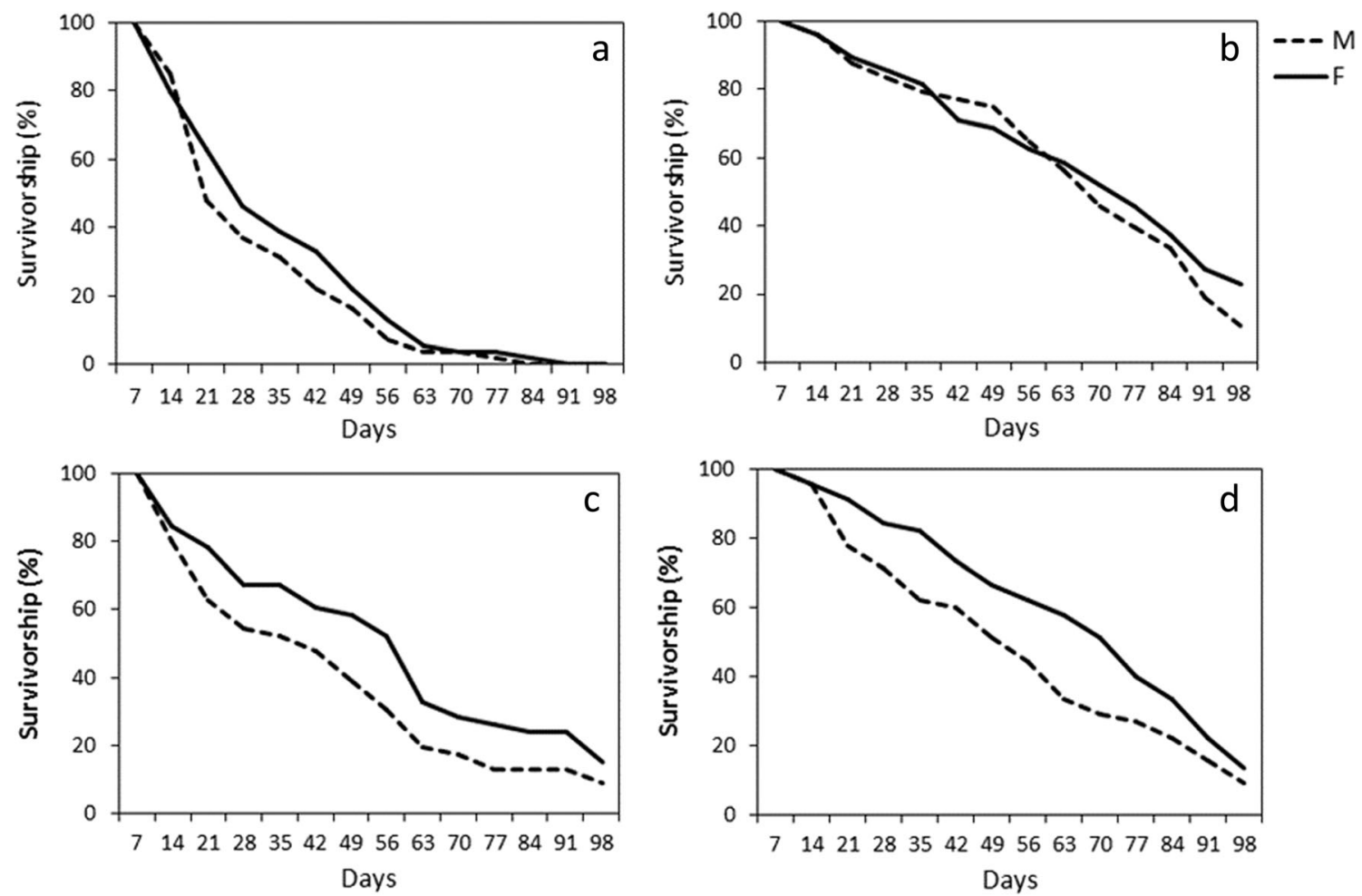

Fig 2 Survivorship (\%) up to 98 days of adults of Piezodorus guildinii feeding on a red clover flower with immature seeds (RCF), b alfalfa immature pods (AIP), c birdsfoot trefoil immature pods (BTIP), and d soybean immature pods (SIP), in the laboratory ( $M$, male; $F$, female). 
Table 3 Slope (b) of de simple linear regression of survivorship and mean ( \pm SEM) longevity of Piezodorus guildinii adults feeding on red clover flower with immature seeds (RCF), birdsfoot trefoil immature pods (BTIP), alfalfa immature pods (AIP), and soybean immature pods (SIP), in the laboratory.

\begin{tabular}{llllll}
\hline Food sources & \multicolumn{2}{l}{$\mathrm{b}^{\mathrm{a}}$} & & \multicolumn{2}{l}{${\text { Longevity }(\text { days })^{\mathrm{b}}}$} \\
\cline { 2 - 3 } \cline { 5 - 6 } & Female & & Male & Female & Male \\
\hline RCF & $-0.053 \pm 0.006 \mathrm{a}$ & $-0.056 \pm 0.005 \mathrm{a}$ & & $33.5 \pm 2.4 \mathrm{C}$ & $29.9 \pm 2.4 \mathrm{C}$ \\
& & & & {$[52]^{\mathrm{c}}$} & {$[53]$} \\
BTIP & $-0.019 \pm 0.003 \mathrm{~b}$ & $-0.025 \pm 0.002 \mathrm{~b}$ & & $56.6 \pm 5.0 \mathrm{~b}$ & $44.5 \pm 4.6 \mathrm{~b}$ \\
& & & & {$[46]$} & {$[45]$} \\
AIP & $-0.015 \pm 0.003 \mathrm{~b}$ & $-0.020 \pm 0.006 \mathrm{~b}$ & & $70.5 \pm 4.7 \mathrm{a}$ & $65.4 \pm 4.5 \mathrm{a}$ \\
& & & & {$[49]$} & {$[48]$} \\
SIP & $-0.018 \pm 0.005 \mathrm{~b}$ & $-0.023 \pm 0.003 \mathrm{~b}$ & & $60.5 \pm 2.9 \mathrm{ab}$ & $47.9 \pm 3.2 \mathrm{~b}$ \\
& & & {$[67]$} & {$[69]$} \\
\hline
\end{tabular}

${ }^{a}$ Slopes expressed as natural logarithm (\% Survivorship +1 ), in each column, followed by the same letters are not significantly different at $p<0.05$ based on $t$ test

${ }^{\mathrm{b}}$ Means in each column followed by the same letters are not significantly different $(p<0.05)$ based on likelihood ratio (number of adults in brackets)

${ }^{\mathrm{C}}$ Number of adults in brackets high ( $88 \%)$. These results may be due to the lack of nutrients that are necessary for normal development and/or the presence of toxic substances such as tannins. These compounds are a major chemical plant defense and are considered anti-nutritional factors, since their presence reduces the digestibility and insects have difficulty to metabolize them (Panizzi \& Silva 2009). This result probably explains in part why Zerbino et al (2014) reported that the total amount of nymphs collected in birdsfoot trefoil was considerably lower than in alfalfa.

Nymph survivorship on SIP and AIP was similar in all instars (second to fifth), ranging between $78-100 \%$ and $76-$ $87 \%$, respectively. However, total nymph mortality on AIP $(\sim 54.2 \%)$ was significantly higher than that obtained on SIP $(32.6 \%)$. These results indicated that SIP is a more suitable food source for nymphs than AIP.

Total nymph mortality recorded on SIP was lower than values reported by Panizzi et al (2000, 2002) and Oliveira
\& Panizzi (2003) $(57.7,88$, and $47.6 \%$, respectively), and similar to that reported by Gómez et al (2013) (38\%) when nymphs received similar food.

These differences may be explained by differences in the quality of food and/or of insects used (Panizzi et al 2002). Usually, nymphs of Piezodorus guildinii have high mortality in all food sources; even in the preferred genus Indigofera nymph mortality was higher than 50\%, except for Indigofera endecaphylla (12\%) (Panizzi 1992).

On food sources in which nymphs completed development (AIP, BTIP, and SIP), the time required to reach adulthood and the fresh body weight at adult emergence did not differ significantly. Values obtained in this experiment were similar to those obtained by Zerbino et al (2013) with other food sources (green pods $P$. vulgaris, soybean seeds, and peanuts) under similar conditions of temperature and light regimes. The fact that adults fed on BTIP had reached a normal size suggests that surviving

Table 4 Reproductive performance of Piezododus guildinii females feeding on red clover flower with immature seeds (RCF), birdsfoot trefoil immature pods (BTIP), alfalfa immature pods (AIP), and soybean immature pods (SIP), in the laboratory.

\begin{tabular}{|c|c|c|c|c|c|}
\hline \multirow[t]{2}{*}{ Food sources } & \multirow[t]{2}{*}{ Females ovipositing (\%) } & \multirow[t]{2}{*}{ Preoviposition period (days) } & \multicolumn{2}{|c|}{ Number/female } & \multirow[t]{2}{*}{ Egg viability (\%) } \\
\hline & & & Egg masses & Eggs & \\
\hline $\mathrm{RCF}$ & 0 & - & - & - & - \\
\hline BTIP & $\begin{array}{l}52.2 b^{a} \\
{[24]^{c}}\end{array}$ & $21.1 \pm 1.6 a b^{a}$ & $4.1 \pm 0.7 b^{a}$ & $60.2 \pm 10.2 b^{a}$ & $58.0 \pm 6.2 a^{b}$ \\
\hline AIP & $\begin{array}{l}87.7 \mathrm{a} \\
{[42]}\end{array}$ & $18.6 \pm 1.8 b$ & $8.5 \pm 1.0 \mathrm{a}$ & $134.4 \pm 16.0 \mathrm{a}$ & $57.5 \pm 3.1 \mathrm{a}$ \\
\hline SIP & $\begin{array}{l}83.8 \text { a } \\
{[62]}\end{array}$ & $25.8 \pm 2.5 \mathrm{a}$ & $9.9 \pm 1.0 \mathrm{a}$ & $148.3 \pm 14.9 \mathrm{a}$ & $58.0 \pm 3.1 \mathrm{a}$ \\
\hline
\end{tabular}

\footnotetext{
${ }^{a}$ Means in each column followed by the same letters are not significantly different $(p<0.05)$ based on likelihood ratio

${ }^{\mathrm{b}}$ Means followed by the same letters do not differ significantly $(p<0.05)$ using Tukey's test

${ }^{\mathrm{c}}$ Number of females that oviposited in brackets
} 
Table 5 Daily weight gain (mg) of Piezodorus guildinii adults during the first 6 weeks of adult life feeding on red clover flower with immature seeds (RCF), birdsfoot trefoil immature pods (BTIP), alfalfa immature pods (AIP), and soybean immature pods (SIP), in the laboratory.

\begin{tabular}{llr}
\hline Food sources & Daily weight gain $(\mathrm{mg})(\mathrm{b})^{\mathrm{a}}$ & $\begin{array}{c}\mathrm{b} \neq 0 \\
P r>t\end{array}$ \\
\hline RCF & $-0.303 \mathrm{c}$ & $<0.0001$ \\
BTIP & $0.035 \mathrm{~b}$ & 0.3501 \\
AIP & $0.181 \mathrm{a}$ & $<0.0001$ \\
SIP & $0.145 \mathrm{a}$ & $<0.0001$ \\
\hline
\end{tabular}

${ }^{a}$ Values in the column followed by the same letters are not significantly different at $p<0.05$ based on $t$ test

nymphs develop mechanisms that allow them to overcome the poor quality of the food (Panizzi et al 2000, 2002).

Food source directly affected adult longevity and percentage of adult survival up to day 98 , as a consequence of the differences in nutritional quality, and indirectly affected reproductive performance as a result of the presence/absence of nutrients that are necessary for egg production (Oliveira \& Panizzi 2003, Panizzi 2007, Panizzi \& Silva 2009). There were also differences in weight gain over a period of 43 days. Weight gain at the beginning of adult life, mainly in the first week, is common among hemipterans (Panizzi \& Slansky 1985, Panizzi 1987). The higher food intake and weight gain during the teneral period in this group are associated with cuticle formation of flight muscles and gonads, and reserve accumulation (Panizzi \& Slansky 1985). In general, weight tends to stabilize after 15 days of adult emergence.

Adults of both sexes that fed on RCF had a survivorship rate and longevity significantly lower than on other food sources; besides, adults lost weight during the first 6 weeks of life. Females did not lay eggs when reared on this food source, and no copulating pairs were observed during their handling. These results demonstrate that RCF is a food
Fig 3 Change in fresh body weight (mean \pm SEM) during the first 6 weeks of adult life and from day 1 to day 43 of Piezodorus guildinii adults feeding on red clover flower with immature seeds (RCF), birdsfoot trefoil immature pods (BTIP), alfalfa immature pods (AIP), and soybean immature pods (SIP), in the laboratory; $\mathbf{a}$ females, and $\mathbf{b}$ males.
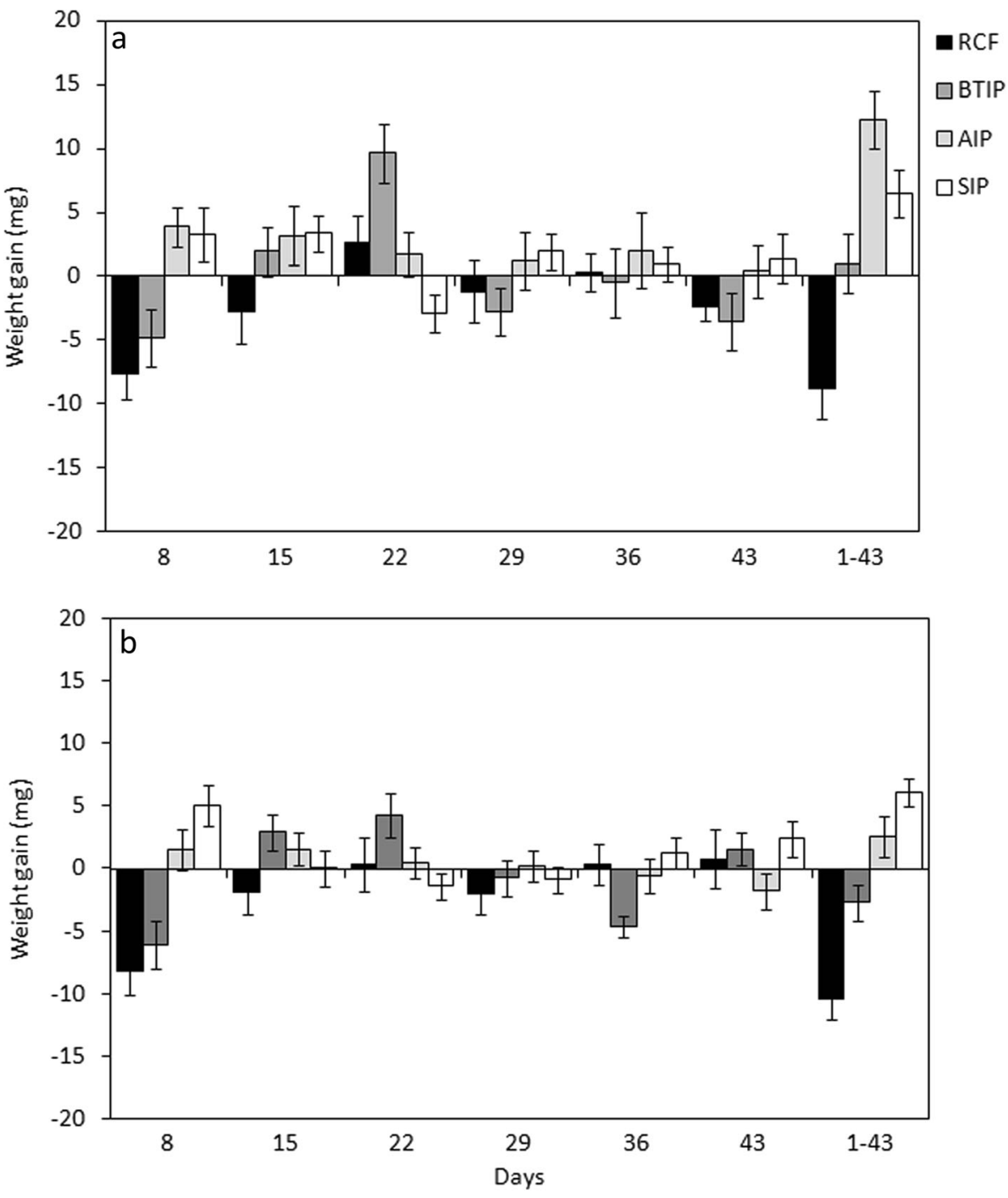
source with low nutritional quality for adults of $P$. guildinii, and reaffirm the hypothesis that adults colonize red clover temporarily in absence of other food sources (Zerbino et al 2014).

Food sources on which $P$. guildinii adult generated offspring (AIP, BTIP, and SIP) had differential effects on adult longevity and reproductive performance; survivorship rate and egg viability were similar in the three food sources. Reproductive performance of females that fed on BTIP was poorer (lower percentage of females ovipositing and lower fecundity) than that observed on AIP and SIP. Furthermore, adults fed on BTIP during the first 43 days did not gain weight. These results are indicating that BTIP has a lower nutritional fitness and demonstrate the importance of the food quality on reproductive performance (Panizzi \& Slansky 1985, Panizzi 1987, 2007, Panizzi et al 2000, 2002, Oliveira \& Panizzi 2003, Gómez et al 2013). The fact that the longevity of adults that fed on BTIP and SIP was similar but had significant differences on reproductive performance indicates that longevity has priority over reproductive activity when the food is nutritionally inadequate; thus, adults save energy (Panizzi et al 2000).

Conversely, alfalfa immature pods (AIP) proved to be a food source with excellent nutritional quality (highest adult longevity, percentage ovipositing females and fecundity, shortest preoviposition period, and furthermore adults gain weight during 43 days). These results indicate that adults fed on this food source accumulate reserves, and the nutrients and energy diverting for egg production do not affect adult lifetime, as it happens with a food with medium and low suitability (Panizzi \& Silva 2009). Differences found in preoviposition period, significantly shorter on AIP than on SIP, suggest that the concentration of compounds involved in the ovary maturation process is higher on AIP than on SIP, and/or AIP may contain other compounds that promote this process (Slansky \& Panizzi 1987). Panizzi \& Slansky (1985) established that the quality of consumed food had effects on the time of oviposition onset. The results obtained about reproductive performance on alfalfa explain why, in general, the abundance of nymphs and adults in this forage legume is higher than in birdsfoot trefoil as determined by Zerbino et al (2014).

The egg viability has proven to be a variable that is not affected by the food consumed by females of $P$. guildinii (Panizzi \& Slansky 1985, Panizzi 1987, 1992, Panizzi et al 2002) or other hemipteran females (Shearer \& Jones 1998, Chocorosqui \& Panizzi 2008).

With the exception of percentage of females that lay eggs and hatching eggs, the values obtained for different reproductive variables when females fed on SIP were within the range reported in other studies (Panizzi \& Slansky 1985, Panizzi et al 2000, 2002, Oliveira \& Panizzi 2003, Gómez et al 2013), in which the food source was soybean pods in a similar growth stage used in this work. The percentage of females ovipositing on SIP (83.7\%) was higher than reported in those studies (30-50\%). Panizzi et al (2000, 2002) and Oliveira \& Panizzi (2003) reported values of egg viability somewhat higher (62 and $75.5 \%$ ) than those recorded in this study (58\%). These differences may be due to the variability in $P$. guildinii populations from different areas and/or the quality of the food source exploited by this insect (Panizzi \& Slansky 1985).

Panizzi (2000) distinguished two groups of plant specieshost plants where phytophagous hemipterans feed, develop, and reproduce; and alternate (associated) plants which are used as shelter and/or as a source of nutrients and water but do not reproduce. According to our data, it was possible to establish the role that different forage legumes have in the life history of $P$. guildinii in Uruguay. Red clover is an associated plant; nymphs do not complete their development and adults do not produce offspring, suggesting that this plant only provides nutrients to sustain the adult life. Birdsfoot trefoil must be regarded as a secondary host plant; although nymphs reach adulthood, mortality is high; furthermore, adult longevity and reproductive performance of females are lower than those fed on alfalfa and soybean. Finally, besides soybean, alfalfa is the most important host plant of $P$. guildinii; although nymph mortality is higher than in soybean, adult longevity and reproductive performance of females are similar to those fed on soybean.

Our results indicate that alfalfa may play a key role in the life history of $P$. guildinii. Therefore, alfalfa is the crop where efforts should be driven to develop and implement tactics during the spring, preventing the buildup of the population that will colonize soybean, and decreasing the impact of this insect pest. Furthermore, in those agroecological regions where alfalfa does not occupy a considerable area, interventions on the secondary host plant birdsfoot trefoil should be planned, as $P$. guildinii fully develops and reproduces.

Acknowledgments We thank Mabel Pessio and Eduardo García for their support working in the laboratory. We gratefully acknowledge two anonymous referees for their critical reading and improving the manuscript. This research is part of a project sponsored by the National Research Council of Brazil (CNPq) in collaboration with INIA of Uruguay.

\section{References}

Chocorosqui VR, Panizzi AR (2008) Nymph and adult biology of Dichelops melacanthus (Dallas) (Heteroptera: Pentatomidae) feeding on cultivated and non-cultivated host plants. Neotrop Entomol 37: 353-360

Gómez VA, Gaona EF, Arias OR, de Lopez MB, Ocampos OE (2013) Aspectos biológicos de Piezodorus guildinii (Westwood) (Hemiptera: Pentatomidae) criados con diferentes dietas en condiciones de laboratorio. Rev Soc Entomol Argent 72:27-34 
Jones WA Jr, Sullivan MJ (1982) Role of host plants in population dynamics of stink bug pests on soybean in South Carolina. Environ Entomol 11:867-875

Kiritani K, Hokyo N, Kimura K, Nakasuji F (1965) Imaginal dispersal of the southern green stink bug, Nezara viridula L., in relation to feeding and oviposition. Jpn J Appl Entomol Zool 9:291-297

Oliveira EDM, Panizzi AR (2003) Performance of nymphs and adults of Piezodorus guildinii (Westwood) (Hemiptera: Pentatomidae) on soybean pods at different developmental stages. Braz Arch Biol Technol 46:187-192

Panizzi AR (1987) Impacto de leguminosas na biologia de ninfas e efeito da troca de alimento no desempenho de adultos de Piezodorus guildinii (Hemiptera: Pentatomidae). Rev Bras Biol 47:585-591

Panizzi AR (1992) Performance of Piezodorus guildinii on four species of Indigofera legumes. Entomol Exp Appl 63:221-228

Panizzi AR (1997) Wild hosts of pentatomids: ecological significance and role in their pest status on crops. Annu Rev Entomol 42:99-122

Panizzi AR (2000) Suboptimal nutrition and feeding behavior of hemipterans on less preferred plant food sources. An Soc Entomol Brasil 29:1-12

Panizzi AR (2007) Nutritional ecology of plant feeding arthropods and IPM. In: Kogan M, Jepson P (eds) Perspectives in ecological theory and pest management. CambridgeUniversity Press, London, pp 170-222

Panizzi AR, Meneguim AM (1989) Performance of nymphal and adult Nezara viridula on selected alternate host plants. Entomol Exp Appl 50:215-223

Panizzi AR, Parra JRP (2009) A bioecologia e a nutrição de insetos como base para o manejo integrado de pragas. In: Panizzi AR, Parra JRP (eds) Bioecologia e nutrição de insetos; base para o manejo de pragas. Embrapa Informacão Tecnológica, Brasilia, pp 1107-1139

Panizzi AR, Parra JRP (2012) Introduction to Insect Bioecology and nutrition for integrated pest management (IPM). In: Panizzi AR, Parra JRP (eds) Insect bioecology and nutrition for integrated pest management. CRC Press, Boca Raton, pp 3-11

Panizzi AR, Silva FAC (2009) Insetos sugadores de sementes (Heteroptera). In: Panizzi AR, Parra JRP (eds) Bioecologia e nutrição de insetos; base para o manejo de pragas. Embrapa Informacão Tecnológica, Brazil, pp 465-522

Panizzi AR, Slansky F Jr (1985) Legume host impact on performance of adult Piezodorus guildinii (Westwood) (Hemiptera: Pentatomidae). Environ Entomol 14:237-242
Panizzi AR, Galileo MHM, Gastal HAO, Toledo JFF, Wild DCH (1980) Dispersal of Nezara viridula and Piezodorus guildinii nymphs in soybeans. Environ Entomol 9:293-297

Panizzi AR, Cardoso SR, Oliveira EDM (2000) Status of pigeonpea as an alternative host or Piezodorus guildinii (Hemiptera: Pentatomidade), a pest of soybean. Fla Entomol 83:334-342

Panizzi AR, Cardoso SR, Chocorosqui VR (2002) Nymph and adult performance of the small green stink bug, Piezodorus guildinii (Westwood) on lanceoeaf crotolaria and soybean. Braz Arch Biol Technol 45:53-58

Ribeiro A, Castiglioni E, Silva H, Bartaburu S (2009) Fluctuaciones poblacionales de pentatómidos (Hemiptera: Pentatomidae) en soja (Glycine max) y lotus (Lotus corniculatus). Bol San Veg Plagas 35: 429-438

SAS Institute (2008) SAS user's guide, release 9.2 ed. SAS Institute, Cary Scriber JM, Slansky F Jr (1981) The nutritional ecology of immature insects. Annu Rev Entomol 26:183-211

Shearer PW, Jones VP (1998) Suitability of selected weeds and groung covers as host plants of Nezara viridula (L.) (Hemiptera: Pentatomidae). Proc Hawaii Entomol Soc 33:75-82

Silva FAC, Panizzi AR (2007) Cotton balls as an oviposition substrate for laboratory rearing of phytophagous stink bugs (Heteroptera: Pentatomidae). Ann Entomol Soc Am 100:745-748

Silva FAC, Panizzi AR (2008) The adequacy of artificial oviposition substrates for laboratory rearing of Piezodorus guildinii (Westwood) (Heteroptera: Pentatomidae). Rev Bras Entomol 52:131-134

Slansky F Jr, Panizzi AR (1987) Nutritional ecology of seed-sucking insects, p. 283-320. In: Slansky F Jr, Rodriguez JG (eds) Nutritional ecology of insects, mites, spiders, and related invertebrates. J. Wiley \& Sons, New York, p 1016

Zerbino MS, Altier N, Panizzi AR (2013) Effect of photoperiod and temperature on nymphal development and adult reproduction of Piezodorus guildinii (Westwood) (Heteroptera: Pentatomidae). Fla Entomol 96:572-582

Zerbino MS, Altier N, Panizzi AR (2014) Seasonal occurrence of Piezodorus guildinii on different plants including morphological and physiological changes. J Pest Sci. doi:10.1007/s10340-014-0630-2 